\title{
Being sensitive to intention-to-treat in medical research
}

\author{
Sahar Khoshkesht ${ }^{1}$, Nahid Dehghan Nayeri ${ }^{* * \mathbb{D}}$ \\ ${ }^{1}$ Department of Medical-Surgical Nursing, School of Nursing and Midwifery, Tehran University of Medical Sciences, Tehran, \\ Iran \\ ${ }^{2}$ Department of Critical Care Nursing and Management, School of Nursing \& Midwifery, Tehran University of Medical \\ Sciences, Tehran, Iran
}

*Corresponding Author: Nahid Dehghan Nayeri, Tel: 98 (21) 61054409 ; Email: dehghann@tums.ac.ir

Received: 18 April 2021, Accepted: 11 May 2021, ePublished: 29 September 2021

\section{Dear Editor}

The purpose of the randomization process in clinical trials is to prevent bias and to ensure comparisons between the two groups in terms of the effect of the intervention (1). However, in some clinical trials, subjects may do not follow interventions, may withdraw from participation, or may be found ineligible after randomization. Accordingly, the elimination of these subjects may result in bias. In general, clinical trials suffer from two major problems of noncompliance and missing outcomes. One of the solutions to this problem is the use of intention-to-treat (ITT) analysis (2).

Therefore, in this letter, the attention of respected researchers is drawn to the basic understanding and application of ITT in order to reduce the likelihood of bias in the results.

ITT means that all involved participants in the randomization process should be analyzed regardless of noncompliance, discontinuation of the study, or failure to follow the intervention, namely, "once random, always analyzing" $(2,3)$. The unwillingness or refusal of treatment may occur in the real world, thus we actually lose part of the data if we do not enter them into the analysis. As recommended in the CONSORT statement, reporting any deviation from randomized allocation and loss of outcomes is necessary (4). ITT analysis is one of Cochrane's key criteria for the publication of articles. The lack of attention to ITT can disrupt the baseline equivalence and may results in non-adherence to the protocol (5). Accordingly, ITT analysis has been accepted as a golden standard for qualified randomized trials.

ITT has several benefits including maintaining prognostic balance, group comparability, and the sample size, as well as testing the effectiveness of intervention rather than the efficacy of the intervention, reducing the type I error, and increasing the probability of generalizability. More precisely, it measures the effect of the treatment without bias. However, the treatment effect should be estimated with caution because of the dilution due to non-compliance and the probability of type II error (2).

One alternative to ITT is per-protocol, implying that the subset of the ITT population having completed their protocol without any major deviations will be analyzed while excluding all those who have not completed treatment. However, it must be interpreted with caution since it blocks the random balance (6). ITT analysis alone is not preferred in non-inferiority trials, both ITT and per-protocol are recommended. But the importance of the ITT analysis in superiority designs is accepted. Nonetheless, for better interpretation, it is recommended that per-protocol be performed after ITT in superiority trials $(2,6)$.

Even many scholars do not use ITT correctly, because it is difficult to deal with mistakes in selecting patients based on the inclusion criteria in the study, noncompliance, and missing data. According to White et al, four strategies exist for performing ITT analysis and dealing with incomplete observations, including attempting to keep following up all the participants, the final analysis of all the observed data, performing sensitivity analysis, and taking into account all the randomized participants in the sensitivity analysis (7).

Finally, it is proposed that researchers be sensitive to missing data and noncompliance problems in their randomized clinical trials so that to reduce the probability of bias and increase study confidence.

Conflict of Interests

Not declared.

Ethical Approval

None to be declared.

(c) 2021 The Author(s); Published by Shahrekord University of Medical Sciences. This is an open-access article distributed under the terms of the Creative Commons Attribution License (http://creativecommons.org/licenses/by/4.0), which permits unrestricted use, distribution, and reproduction in any medium, provided the original work is properly cited. 


\section{References}

1. Mansournia MA, Higgins JP, Sterne JA, Hernán MA. Biases in randomized trials: a conversation between trialists and epidemiologists. Epidemiology. 2017;28(1):54-9. doi: 10.1097/ede.0000000000000564.

2. Gupta SK. Intention-to-treat concept: a review. Perspect Clin Res. 2011;2(3):109-12. doi: 10.4103/2229-3485.83221.

3. McCoy CE. Understanding the intention-to-treat principle in randomized controlled trials. West J Emerg Med. 2017;18(6):1075-8. doi: 10.5811/westjem.2017.8.35985.

4. Schulz KF, Altman DG, Moher D. CONSORT 2010 statement: updated guidelines for reporting parallel group randomised trials. BMC Med. 2010;8:18. doi: 10.1186/1741-
7015-8-18.

5. Higgins JPT, Green S. Cochrane Handbook for Systematic Reviews of Interventions. Version 5.1.0. The Cochrane Collaboration; 2011. Available from: https://training. cochrane.org/handbook. Updated March 2011.

6. Ranganathan P, Pramesh CS, Aggarwal R. Common pitfalls in statistical analysis: Intention-to-treat versus perprotocol analysis. Perspect Clin Res. 2016;7(3):144-6. doi: 10.4103/2229-3485.184823.

7. White IR, Horton NJ, Carpenter J, Pocock SJ. Strategy for intention to treat analysis in randomised trials with missing outcome data. BMJ. 2011;342:d40. doi: 10.1136/bmj.d40. 